\section{Rooting Oak Cuttings from Gibberellin-treated Stock Plants}

\author{
Yuval Eshed and Joseph Riov \\ Department of Horticulture, Faculty of Agriculture, The Hebrew University of
} Jerusalem, P.O. Box 12, Rehovot 76100, Israel

Nir Atzmon

Department of Natural Resources, Institute of Field and Garden Crops, The Volcani Center, P.O. Box 6, Bet Dagan 50250, Israel

Additional index words. Quercus ithaburensis, propagation, juvenility

Abstract. Rooting of Quercus ithaburensis Deche. cuttings decreased significantly with increasing stock plant age. Gibberellin $\left(\mathrm{GA}_{3}\right)$ applied as bark treatment on leafless pruned stems of 3-year-old stock plants improved rooting percentage 6- to 7-fold. GA 3 application also enhanced bud release and particularly shoot growth, thus increasing the number of cuttings per stock plant.

Oaks (Quercus spp.) are highly heterozygous and exhibit high genetic variation. Attempts to propagate oaks from stem cuttings for obtaining clonal material have had limited success. Juvenile cuttings taken from oak seedlings root quite easily but oaks lose juvenility very rapidly, resulting in reduced rooting capability (Morgan and McWilliams, 1976). Stock plant etiolation and blanching before cutting propagation (Eshed, 1991) and use of rooted cuttings as stock plants (Morgan et al., 1980) have improved the rooting of oak cuttings.

Gibberellins are often associated with juvenility, and application of gibberellins to several species in the mature phase induces some juvenile characteristics (Hackett, 1985). $\mathrm{GA}_{3}$ treatment of mature stock plants of avocado (Persea americana Mill.) (Cutting and Van Vuuren, 1988) and citrus (Sagee et al., 1990) significantly improved the rooting of cuttings. The aim of the present study was to examine the possibility to improve rooting of Quercus ithaburensis cuttings by treating stock plants with gibberellin. Quercus ithaburensis was chosen as representative of the East Mediterranean oaks.

\section{Materials and Methods}

One-, 2-, and 3-year-old seedlings of $Q$. ithaburensis were grown in an open nursery in 3-L containers using a mixture of 7 peat : 3 perlite $(\mathrm{v} / \mathrm{v})$. Seedlings were fertilized with $7 \mathrm{~N}-3 \mathrm{P}-7 \mathrm{~K}$ at $100 \mathrm{mg} \cdot \mathrm{L}^{-1}$ through the drip irrigation system.

\footnotetext{
Received for publication 25 Oct. 1995. Accepted for publication 15 Apr. 1996. This research was supported by the Joint Dutch-Israeli Agricultural Research Program (DIARP). Contribution from the Agricultural Research Organization, The Volcani Center, Bet Dagan, Israel. No. 1723-E, 1995 series. The cost of publishing this paper was defrayed in part by the payment of page charges. Under postal regulations, this paper therefore must be hereby marked advertisement solely to indicate this fact.
}

$\mathrm{GA}_{3}$ (Sigma Chemical Co., St. Louis) was applied in April by means of a lanolin (BDH, Poole, England) paste. The lanolin paste was prepared by heating the lanolin to $50{ }^{\circ} \mathrm{C}$ and adding the desired concentration (w/w) of $\mathrm{GA}_{3}$, dissolved in methanol, with constant stirring. Immediately after complete top pruning to about $10 \mathrm{~cm}$ above the growing medium, leaving one leafless stem, the paste was applied 1$)$ on top of the cut surface $(\approx 250 \mathrm{mg}$ ) or 2) around the stem to a length of $2 \mathrm{~cm}(\approx 400$ $\mathrm{mg}) 2$ to $3 \mathrm{~cm}$ above the growing medium (bark treatment). Ten stock plants were used for each treatment.

The number of shoots was recorded 4 weeks after pruning and 60 apical and subapical cuttings were harvested. The two types of cuttings were pooled because Eshed (1991) has shown that apical and subapical cuttings of $Q$. ithaburensis root similarly. Cuttings were $\approx 10 \mathrm{~cm}$ long and 4 to $6 \mathrm{~mm}$ thick, with about four leaves. The base of the cuttings was treated with commercial rooting powder containing $0.8 \%$ indole-3-butyric acid (IBA).

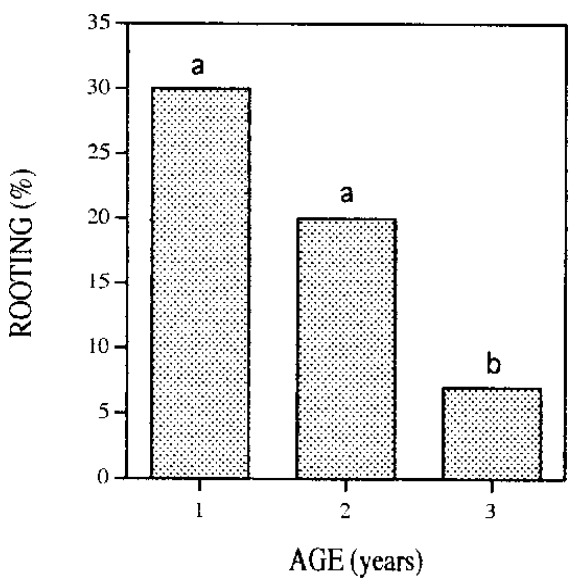

Fig. 1. Rooting percentage of cuttings from nontreated stock plants of Quercus ithaburensis as affected by stock plant age. Bars followed by the same letter are not significantly different at $P \leq 0.05(\mathrm{n}=60)$.
Cuttings were rooted in an even mixture of vermiculite : perlite (v/v) and held at $24 \pm 1^{\circ} \mathrm{C}$. Cuttings were misted for $5 \mathrm{~s}$ every $10 \mathrm{~min}$. The rooting percentage was recorded after 6 weeks. Experiments were repeated several times over 3 years.

Analysis of variance was performed on arcsin-transformed square roots of proportion.

\section{Results and Discussion}

Stock plant age had a significant effect on rooting of cuttings. Rooting percentage of cuttings from nontreated stock plants dropped from $30 \%$ in cuttings from 1 -year-old plants to $7 \%$ in cuttings from 3-year-old plants (Fig. 1). Cuttings from 9-year-old stock plants showed the same rooting ability as those from 3-yearold plants (data not shown).

All $\mathrm{GA}_{3}$ concentrations applied as bark treatment to 3-year-old stock plants increased rooting over the control by 6-to 7-fold (Fig. 2). No significant difference was found between $\mathrm{GA}_{3}$ at 500, 1000, and $2000 \mathrm{mg} \cdot \mathrm{L}^{-1}$. Application of $\mathrm{GA}_{3}$ to the cut surface of pruned stems immediately after pruning did not significantly increase the rooting of cuttings (data not shown).

There was a trend for increasing number of new shoots formed following treatment with increasing GA concentrations. However, the difference between the treatments and the control was not statistically significant. In addition, the percentage of long shoots (longer than $10 \mathrm{~cm}$, the minimum length of cutting) was significantly higher in $\mathrm{GA}_{3}$-treated plants. $\mathrm{GA}_{3}$ at 500 and $1000 \mathrm{mg} \cdot \mathrm{L}^{-1}$ increased the percentage of long shoots from $35 \%$ in control plants to $\approx 60 \%$.

Quercus ithaburensis quickly loses its rooting ability with increasing stock plant age (Fig. 1). $\mathrm{GA}_{3}$ treatment of stock plants not only restored the rooting ability but significantly increased it above the control (Fig. 2). Since $\mathrm{GA}_{3}$ treatment was effective in 3-year-old oak seedlings, which, according to their rooting

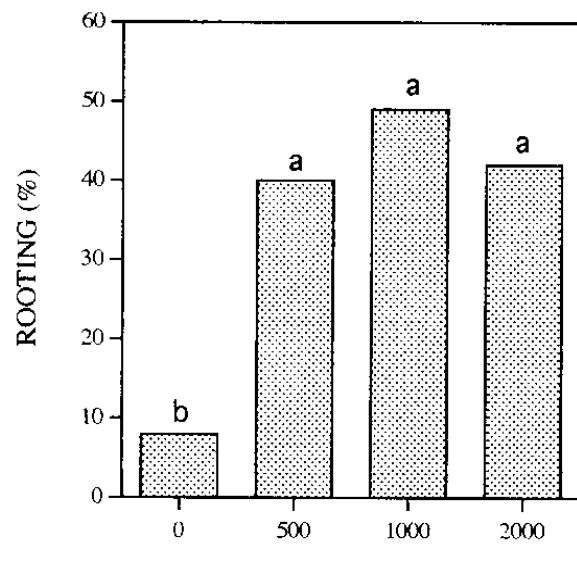

GA3 CONCENTRATION (mg.L- l)

Fig. 2. Effect of $\mathrm{GA}_{3}$ concentration on rooting percentage of 3-year-old cuttings of Quercus ithaburensis. Bars followed by the same letter are not significantly different at $P \leq 0.05$ (n = $60)$. 
ability, were probably in the mature phase, it is reasonable to assume that the rootingpromotive effect of $\mathrm{GA}_{3}$ resulted from a rejuvenation effect. This assumption is supported by the observations that $\mathrm{GA}_{3}$ induces morphological and physiological changes characteristic of the juvenile phase in mature plants of several species (Hackett, 1985). The rootingpromotive effect of $\mathrm{GA}_{3}$ following application to stock plants should be distinguished from its inhibitory effect on rooting when applied to cuttings before rooting (Hartmann et al., 1990).

Our study points to the possibility of using GA application to oak stock plants to improve rooting of cuttings. This method seems to have an advantage over those previously reported, such as etiolation (Eshed, 1991) and use of rooted cuttings as stock plants (Morgan et al., 1980), since $\mathrm{GA}_{3}$ not only improves rooting but also increases the number of cuttings available from the stock plants.

\section{Literature Cited}

Cutting, J.G.M. and S.P. Van Vuuren. 1988. Rooting leafy non-etiolated avocado cuttings from gibberellin-injected trees. Scientia Hort. 37:171176.

Eshed, Y. 1991. Propagation of oaks from acorns and cuttings. MS Thesis, Hebrew Univ. of Jerusalem. Hackett, W.P. 1985. Juvenility, maturation, and rejuvenation in woody plants. Hort. Rev. 7:109155.

Hartmann, H.T., K.D. Kester, and F.T. Davies. 1990. Plant propagation: Principles and practices. Prentice-Hall, Englewood Cliffs, N.J.

Morgan, D.L. and E.L. McWilliams. 1976. Juvenility as a factor in propagation of Quercus virginiana Mill. Acta Hort. 56:263-268.

Morgan, D.L., E.L. McWilliams, and W.C. Parr. 1980. Maintaining juvenility in live oak. HortScience 15:493-494.

Sagee, O., A. Shaked, and D. Hasdai. 1990. Rooting of cuttings from gibberellin and benzyladeninetreated citrus trees. J. Hort. Sci. 65:473-478. 